\title{
Patient and National Economic Burden of Dengue in Japan: Results from Japanese National Claims Database
}

\author{
Yusuke Kajimoto ${ }^{1,2 \star}$ and Tsutomu Kitajima ${ }^{3}$ \\ ${ }^{1}$ Graduate School of Pharmaceutical Sciences, Tokyo University, Tokyo, Japan; ${ }^{2}$ Global Health Research Coordinating Center, Kanagawa Institute \\ of Industrial Science and Technology, Tokyo, Japan; ${ }^{3}$ Faculty of Social Sciences, Kyorin University, Tokyo, Japan
}

\begin{abstract}
Dengue fever is a predominantly imported infectious disease in Japan. However, domestic dengue infections were found in 2014. The economic burden of dengue is informative to formulate a policy toward its control. We estimated patient and societal economic burden of dengue infections in Japan from the restricted societal perspective. The direct medical cost was estimated from the national claims database between 2011 and 2015, and the indirect cost was estimated by multiplying the treatment days with the average wage. The average number of dengue patients per year was 274. The economic burden per dengue patient was $\$ 1,364.90$ (direct medical cost: $\$ 1,213.80$ and indirect cost: $\$ 151.10$ ); the average economic burden for dengue in Japan per year was $\$ 433,217$ (direct cost: $\$ 329,557$, indirect cost: $\$ 41,298$, and nonmedical cost: $\$ 62,362)$. We estimated the economic burden of dengue per patient and year in Japan from 2011 to 2015 . The economic burden per year was not huge. It may not be necessary to formulate the National Prevention Plan for dengue. However, domestic dengue outbreak might occur again in the future. Preventive action should be taken with considering cost-effectiveness or budget impact. The findings in this study may be of use for these health economic analyses for planning prevention strategy for not only dengue but also other mosquito-borne diseases.
\end{abstract}

\section{INTRODUCTION}

Dengue fever (DF) is a mosquito-borne disease transmitted by Aedes aegypti and Aedes albopictus. Its common symptoms are high fever, headache, vomiting, myalgia, macular rash, and decreased platelet count. ${ }^{1,2}$ Usually, the patient recovers from dengue infection within a few weeks. Dengue fever is classified as dengue without warning signs; dengue with warning signs; or severe dengue under dengue guidelines for diagnosis, treatment, prevention and control, and the International Classification of Diseases (ICD)-11, which was published by the WHO. In ICD-10, dengue infection was categorized as DF or dengue hemorrhagic fever (DHF). There are 96 million symptomatic dengue infections, mostly in South Asia and Southeast Asia, ${ }^{3}$ and 128 countries are at infection risk. ${ }^{4}$ The more the habitats of the vectors spread due to climate change, the more the people would be at risk of the infection. In Japan, DF is a predominantly imported infectious disease ${ }^{5}$ and designated as a class IV infectious disease under the Act on the Prevention of Infectious Diseases and Medical Care for Patients with Infectious Diseases (hereafter the Infectious Diseases Act). ${ }^{6}$ All dengue cases are reported as DF or DHF in accordance with the Infectious Diseases Act. Domestic dengue infections had not been found since 1945 when soldiers came back from dengue-epidemic areas after World War II. ${ }^{5}$ However, in 2014, 162 domestic dengue infections were found. Because of rapid globalization and global warming, its vectors, Ae. albopictus mosquitoes, are expanding into the northernmost region of the main island of Japan. ${ }^{7}$ The primary transmitter of dengue virus in the world is Ae. aegypti, and the vector is a more efficient transmitter than Ae albopictus. ${ }^{8}$ Although $A e$. aegypti is currently not observed in Japan, model simulation considering global warming showed possibility of expanding distribution up to the southern part of Japan, such as Kyushu and Shikoku islands. ${ }^{9}$ It is possible to have more dengue cases because of domestic infections in the future. A woman who

*Address correspondence to Yusuke Kajimoto, Graduate School of Pharmaceutical Sciences, The University of Tokyo, 7-3-1 Hongo, Bunkyo-ku, Tokyo 113-0033, Japan. E-mail: ykajimoto234@gmail.com lived in Berlin, Germany, was diagnosed with dengue soon after returning from Japan in $2013 .^{10}$ She incurred several mosquito bites when picking grapes in Fuefuki in Japan. The case implied that domestic dengue infections might have occurred, but they had not been diagnosed and reported in Japan.

The cost of illness of DF is an important information to formulate a policy toward its control. Direct cost can be divided into direct medical cost and direct nonmedical cost. Direct medical cost is associated with medical resources, such as treatment, admission, and blood test. Direct nonmedical cost consists of costs not directly related to medical services but necessary for receiving such services, such as transportation to a hospital. Indirect cost represents productivity loss due to symptoms of a disease or hospitalization. These costs are an economic burden on the patient, healthcare system, and society. The cost of illness can be used for cost-effective analysis or budget impact analysis of dengue prevention plans including vaccination. Dengue-endemic countries, such as Brazil, ${ }^{11}$ Colombia, ${ }^{12}$ India, ${ }^{13,14}$ and Mexico, ${ }^{15}$ have estimated the economic burden of dengue. Their economic burden at the national level was so huge that a cost-effective prevention was urgently required. There are currently considerably fewer dengue patients in Japan than in those countries. Notwithstanding, we might have more dengue infections in Japan in the near future due to climate change and the growth of tourism. Therefore, the cost of illness of dengue would be informative when the Japanese or local government plans for preventive actions. Thus, the objective of this research is to estimate the economic burden of dengue infections in Japan.

\section{METHODS}

Research design. We used the National Database of Health Insurance Claims and Specific Health Checkups of Japan (NDB) to estimate the economic burden of dengue between 2011 and 2015. The public insurance covered 127,047 thousand people as of June $2011,{ }^{16}$ and the Japanese population as of October 2011 was 127,799 thousand. ${ }^{17}$ Almost all people in Japan are covered by public health 
insurance. The NDB covered $99.9 \%$ of claims of public insurance from hospitals and pharmacies and $97.9 \%$ issued from clinics as of May 2015. ${ }^{18}$ The claims data represent the total direct medical cost from the restricted societal perspective, excluding the patients who treat themselves. Private insurance plays a complementary role in financing medical services in Japan. Private insurance may alleviate a burden on co-payment of each patient, but it does not influence costs from the restricted societal perspective in the Japanese insurance system. Therefore, private insurance was not considered in this research.

The NDB has two categories for dengue infection, which are DF and DHF. Dengue fever is diagnosed by dengue nonstructural protein 1 antigen ELISA and other tests, such as reverse transcription-polymerase chain reaction. Dengue hemorrhagic fever is diagnosed when a DF patient meets the following four criteria: 1) fever continuing for 2-7 days; 2) one or more symptoms of increased hematocrit, shock, decreased serum protein/presence of pleural effusion, or ascites; 3) decreased platelet $\left(<100,000 / \mathrm{mm}^{3}\right)$; and 4 ) one or more symptoms of positive for tourniquet test, petechiae bleeding/patchy ecchymoses/purpura, mucosal or gastrointestinal bleeding/ bleeding at injection site or any other site, or blood in stool. ${ }^{19}$

Extraction of dengue patients from the NDB. The insurance claim data that were matched with "DF" or "DHF" as a disease name without suspicious disease flag were extracted from the NDB between 2011 and 2015. The extracted data include age, gender, payment, inpatient or outpatient number of days, and disease names or symptoms. To estimate dengue-specific cost, the patients who had lifestyle diseases, chronic diseases, tumor and congenital diseases, diseases temporally not associated with dengue, other infections, allergy and a disease whose association with dengue can be denied by other causes, and uncoded disease name on the NDB were excluded.

The number of dengue patients. All dengue cases must be reported in accordance with the Infectious Diseases Act. The numbers of the dengue patients under the Infectious Diseases Act from 2011 to 2015 were 113, 221, 249, 341, and 293, respectively. ${ }^{20-24}$ To confirm whether the number of claims data was credible, we analyzed the correlation between the number of patients from claims data and the infection report under the Infectious Disease Act each year.

Cost analysis. We estimated the economic burden of dengue in Japan from the restricted societal perspective. The economic burden in this research consists of direct medical cost and indirect cost of DF. The direct medical costs were estimated from payment data from the NDB. We estimated the indirect cost by multiplying the number of treatment days with the average wage reported in the Basic Survey on Wage Structure for 20- to 69 -year-olds. ${ }^{25-29}$ For those younger than 20 and older than 69 years, indirect costs were estimated by multiplying the number of patient's treatment days with the average female wage. We estimated direct medical cost and indirect cost per patient. We also estimated these costs by gender, age-group, DF or DHF, and inpatient or outpatient, respectively. We showed the distribution as a histogram of direct medical cost per patient by inpatient and outpatient. When claims of the same patient were made over a calendar year, the year that the first claim was made was considered as an onset year. Annual change in direct medical cost per patient was analyzed using the onset year. The estimated national annual economic burden was calculated by multiplying the direct medical cost and indirect cost per patient by the total number of dengue patients on the NDB, and added the estimated direct and indirect costs of nonmedical cases who selftreated by over-the-counter remedy. In this research, we used $34 \%$ of the total reported dengue cases as the number of nonmedical cases. ${ }^{30}$ Its direct cost and indirect cost per patient were \$6 and \$458, respectively. The median between 2011 and 2015 of Purchasing Power Parities on the Organization for Economic Cooperation and Development statistics was used as the exchange rate (USD $1=$ JPY 103.05). ${ }^{31}$

Statistical analysis. We used Spearman's rank correlation coefficient to test the correlation between the number of the extracted claim data and the infection report under the Infections Disease Act. We used the Mann-Whitney test to investigate the differences in direct medical cost by gender, DF and DHF, and inpatient and outpatient. We used the Kruskal-Wallis test as two-sided testing to compare the difference by age-group. R version 3.5.2 (the R Foundation for Statistical Computing, Vienna, Austria) was used for statistical analysis. $P$-values of less than 0.05 were considered significant.

Sensitivity analysis. To simulate maximum and minimum annual economic burden with the uncertainty of fluctuating parameters, a one-way sensitivity analysis for the annual national economic burden of dengue in Japan was implemented for two scenarios: a) actual number of patients from the NDB and $b$ ) number of patients adjusted for underreported cases who were not tested for dengue. The reporting rate of dengue was $24.2 \%$ in Singapore. ${ }^{32}$ Singapore has a sophisticated health system and the most similar medical situation with Japan among Southeast Asian countries. We calculated the estimated total number of dengue using $24.2 \%$ for the reporting rate. The parameters for the sensitivity analysis were the number of patients, direct medical cost of medical cases, indirect cost of medical cases, and costs of nonmedical cases. We used SD in the scenario a) and $95 \% \mathrm{Cl}$ in the scenario b) for the number of patients. For direct medical cost, patients with comorbidities should have higher direct medical cost than those without comorbidities because of various symptoms from combination with dengue. Patients with comorbidities not related to dengue were excluded in this research. We used our result of direct medical cost per patient among those with only dengue infection as minimum direct medical cost and direct medical cost per patient among those including patients who had comorbidities as maximum direct medical cost. The range for nonmedical direct and indirect cost was $95 \% \mathrm{Cl}$ from the ref. 30 . The range of indirect cost of medical cases was 50-200\% of their average between 2011 and 2015.

\section{RESULTS}

Number of patients and correlation with infection report. The total number of dengue patients in the NDB was 1370, which consisted of 193, 230, 293, 353, and 301 from 2011 to 2015, respectively. A correlation coefficient of the number of dengue patients between the NDB and the infection report under the Infectious Disease Act was $0.92(P=0.01)$.

Data extraction. We excluded 512 patients who had an unrelated disease name with dengue from the total dengue patients (Table 1). The data of the remaining 858 patients were 
TABLE 1

The number of cases excluded from the analysis by disease name

\begin{tabular}{lc}
\hline \multicolumn{1}{c}{ Disease name } & Number \\
\hline Lifestyle disease & \\
Hypertension & 39 \\
Diabetes & 32 \\
Hyperlipidemia & 23 \\
Hyperuricemia & 17 \\
Hypercholesterolemia & 12 \\
Dyslipidemia & 12 \\
Type 2 diabetes & 11 \\
Type 2 diabetes without diabetic & 10 \\
complication & \\
Fatty liver & 10 \\
Other infection & \\
Bacterial enteritis & 27 \\
Malaria & 12 \\
Epstein-Barr virus infection & 11 \\
Bacteremia & 11 \\
Influenza & 11 \\
Infectious mononucleosis & 11 \\
Escherichia coli infection & 10 \\
Allergy & \\
Allergic rhinitis & 54 \\
Bronchial asthma & 22 \\
Toxicodermatitis & 21 \\
Allergic dermatitis & 17 \\
Allergic urticaria & 11 \\
Allergic conjunctivitis & 11 \\
Chronic disease & \\
Chronic gastritis & 35 \\
Tumor & $-{ }^{*}$ \\
Congenital disease & $-{ }^{*}$ \\
Disease whose association can be denied & 25 \\
Myopic astigmatism & 73 \\
Uncoded disease name & \\
\hline Less than 10 patients are not allowed to be shown according to the guidelines of the \\
National Database of Health Insurance Claims and Specific Health Checkups of Japan. \\
${ }^{*}$ Numbers of each disease name were less than 10. \\
\end{tabular}

used for this analysis. The numbers of patients from 2011 to 2015 were 105, 147, 177, 224, and 205, respectively.

Cost analysis (economic burden per patient) distribution. Table 2 shows the direct medical cost per patient. The average and median direct medical cost per patient was $\$ 1,213.80$ and $\$ 301.60$, respectively. Differences in the direct medical cost by age-groups, DF/DHF, and inpatient/outpatient were significant.

The average days of hospital stay and visit were 4.9 (8.6 days as inpatient and 2.4 days as outpatient). Based on these data, the average and median indirect cost per patient were estimated to be $\$ 151.10$ and $\$ 130.50$, respectively. Figure 1 shows the distribution of inpatient and outpatient.
Cost analysis (annual economic burden in Japan) sensitivity analysis. The total number of nonmedical cases was estimated to be 705 patients (2011: 99, 2012: 118, 2013: 150, 2014:182, and 2015: 155). The estimated average annual economic burden of dengue in Japan from 2011 to 2015 was $\$ 433,217$ (direct medical cost: $\$ 329,557$, indirect cost: $\$ 41,298$, and nonmedical cost: $\$ 62,362$ ) (Figure 2). The annual economic burden in each year was $\$ 230,849$ (direct medical cost: $\$ 157,382$, indirect cost: $\$ 27,531$, and nonmedical cost: $\$ 45,936$ ) in 2011, $\$ 360,971$ (direct medical cost: $\$ 270,358$, indirect cost: $\$ 35,861$, and nonmedical cost: $\$ 54,752)$ in 2012 , $\$ 442,204$ (direct medical cost: $\$ 344,937$, indirect cost: $\$ 42,515$, and nonmedical cost: $\$ 54,752$ ) in $2013, \$ 596,008$ (direct medical cost: $\$ 459,765$, indirect cost: $\$ 51,795$, and nonmedical cost: $\$ 84,448$ ) in 2014, and $\$ 536,054$ (direct medical cost: $\$ 415,344$, indirect cost: $\$ 48,790$, and nonmedical cost: \$71,920) in 2015.

Parameters for one-way sensitivity analysis are shown in Table 3 and the results in Figure 3 . The maximum cost per year in scenarios (a) and (b) was $\$ 765,929$ and $\$ 1,369,016$, respectively. The parameters for sensitivity analysis from the most influential factor were a combination of all parameters, number of patients, direct medical cost of medical cases, costs of nonmedical cases, and indirect cost of medical cases in both scenarios (a) and (b).

\section{DISCUSSION}

This research estimated the cost of illness of dengue per patient and year in Japan between 2011 and 2015.

The correlation coefficient between the number of patients of the NDB and the infection report under the Infectious Diseases Act is very strong and significant $(r=0.92, P=0.01)$. The number of dengue patients in the NDB was slightly larger than that in the report under the Infectious Diseases Act. This difference is plausible because some of the clinicians who diagnosed dengue patients might have failed to report them to the health authority, although they rarely fail to submit the claims of these patients to insurers. We, therefore, regarded that the NDB was credible for cost analysis.

The studies in other countries that estimated the cost of illness of dengue had varying results. Direct medical cost per outpatient case was \$33-\$168 (including direct nonmedical cost) in Brazil, ${ }^{11} \$ 13.3$ (households) in Colombia, ${ }^{12} \$ 25.46$ in India, ${ }^{13}$ and $\$ 253$ in Mexico, ${ }^{15}$ respectively. Direct medical cost per inpatient was \$198-\$906 in Brazil, \$34.80 for DF and

TABLE 2

Direct medical cost per patient and difference between each subgroup

\begin{tabular}{lcccc}
\hline \multicolumn{1}{c}{ Category } & $n$ & Average, US $\$(S D)$ & Median, US\$(25th and 75th percentile) & $P$-value \\
\hline Total & 858 & $1,213.8(1,813.2)$ & $301.6(143.8,2,094.0)$ & - \\
Male & 525 & $1,139.3(1.550 .9)$ & $303.3(145.0,1,999.3)$ & $294.2(141.6,2,319.9)$ \\
Female & 333 & $1,331.3(2,157.8)$ & $497.9(176.5,2,587.3)$ \\
Age-group (years) 0-19 & 121 & $1,492.9(1,706.9)$ & $304.6(141.5,2,134.6)$ \\
Age-group (years) 20-39 & 467 & $1,206.2(1,810.1)$ & $243.3(136.1,1,771.6)$ \\
Age-group (years) 40-59 & 220 & $1,067.8(1,908.2)$ & $288.5(174.2,2,387.7)$ \\
Age (years) 60+ & 50 & $1,250.9(1,567.5)$ & $284.8(141.3,2,041.8)$ \\
DF & 828 & $1,155.5(1,719.8)$ & $2,144.1(640.9,3,533.4)$ \\
DHF & 30 & $2,821.3(3,116.7)$ & $2,462.3(1,838.8,3,166.7)$ \\
Inpatient & 338 & $2,775.2(2,071.8)$ & $172.7(104.8,250.8)$ \\
Outpatient & 520 & $198.9(140.2)$ & $<0.001$ \\
\hline DF = dengue fever; DHF = dengue hemorrhage fever. The Mann-Whitney U test was performed to compare differences for gender, DF/DHF, and inpatient/outpatient. The Kruskal-Wallis test was \\
performed to compare between ages.
\end{tabular}




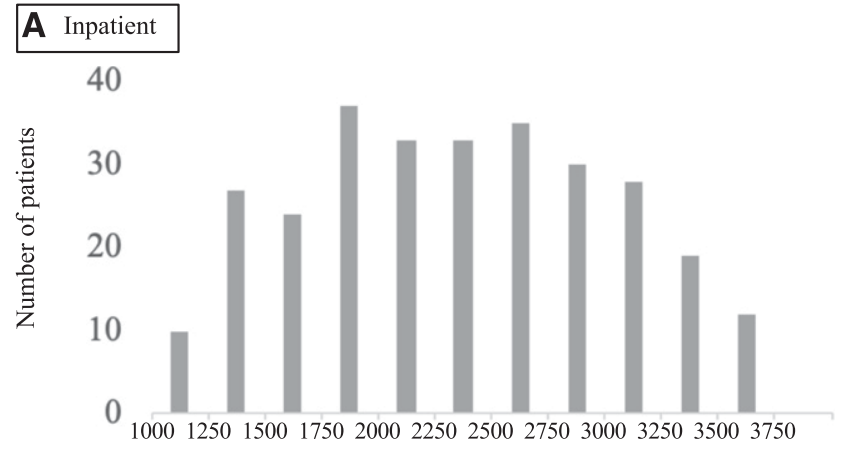

Direct medical cost (\$)

\section{B Outpatient}

120

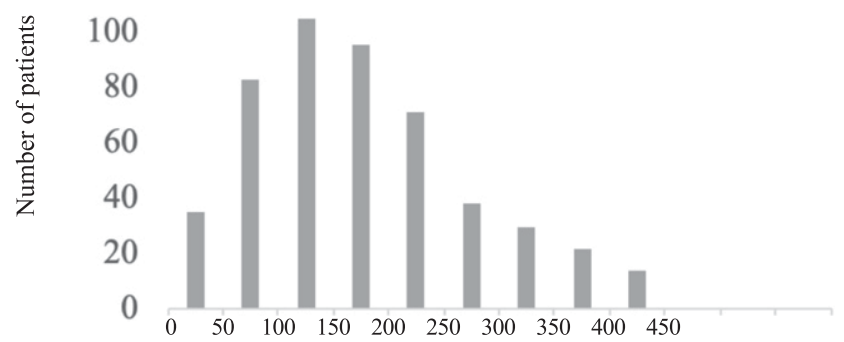

Direct medical cost $(\$)$

FIGURE 1. Distribution of direct cost by inpatient and outpatient.

$\$ 57.30$ for DHF in Colombia, $\$ 235.20$ in India, and $\$ 1,010$ in Mexico. Another study in India showed that the cost per case was $\$ 312.75$ for dengue without warning signs in adults, $\$ 287.22$ for dengue with warning signs, and $\$ 720.39$ for severe dengue. ${ }^{14}$ Our result showed that direct medical cost in Japan was much higher for both outpatient and inpatient than in other countries. An important factor for this reason would be that costs of human resources and medical supplies in Japan are generally more expensive than those in other countries mentioned earlier. However, the patients themselves had lesser economic burden because nearly all the residents in Japan are covered by public health insurance schemes, in which patients, depending on their age and income, pay between $10 \%$ and $30 \%$ of medical fees at health facilities. In addition, the Japanese public insurance system has a "high-cost medical expense benefit" which provides a ceiling amount to the patient's co-payment. Private insurance may also support out-of-pocket payment or loss of income. Another possibility of this difference is that we could not exclude the dengue patients who had comorbidities with high medical cost such as liver dysfunction or renal failure from the analysis because disease names available in the NDB did not allow us to rule out the relationship between dengue and these comorbidities. On the other hand, actual direct medical cost and indirect cost per patient might be higher than our results because patients with comorbidities not related to dengue were excluded. Patients with comorbidities might have had more severe symptoms and longer treatment days.

Cost for dengue per year in Japan was much smaller than that of endemic countries because Japan had fewer cases than those countries. Dengue has been predominantly an imported disease in Japan.

Dengue vaccine was not available in Japan as of 2019. A dengue vaccine, Dengvaxia (Sanofi Pasteur Inc., Lyon, France), requires three doses 6 months apart, and it has efficacy with long-term protection in seropositive individuals and is not recommended for seronegative population because of the tendency of severe dengue. ${ }^{33}$ The vaccine may be useful for individuals with seropositive status and frequently traveling to or living in endemic countries, but it is unlikely to be useful and cost-effective for general Japanese population.

Nonmedical cases were considered in this research. Nonsteroidal anti-inflammatory drugs (NSAIDs) are popular analgesic antipyretics as an over-the-counter remedy, and $13.2 \%$ of medical cases used NSAIDs. ${ }^{34}$ The use of NSAIDs elevates the risk of having severe symptoms of dengue, which may increase the economic burden for dengue. It is important to provide this information with both medical staff and patients with high fever soon after returning from dengue-endemic areas.

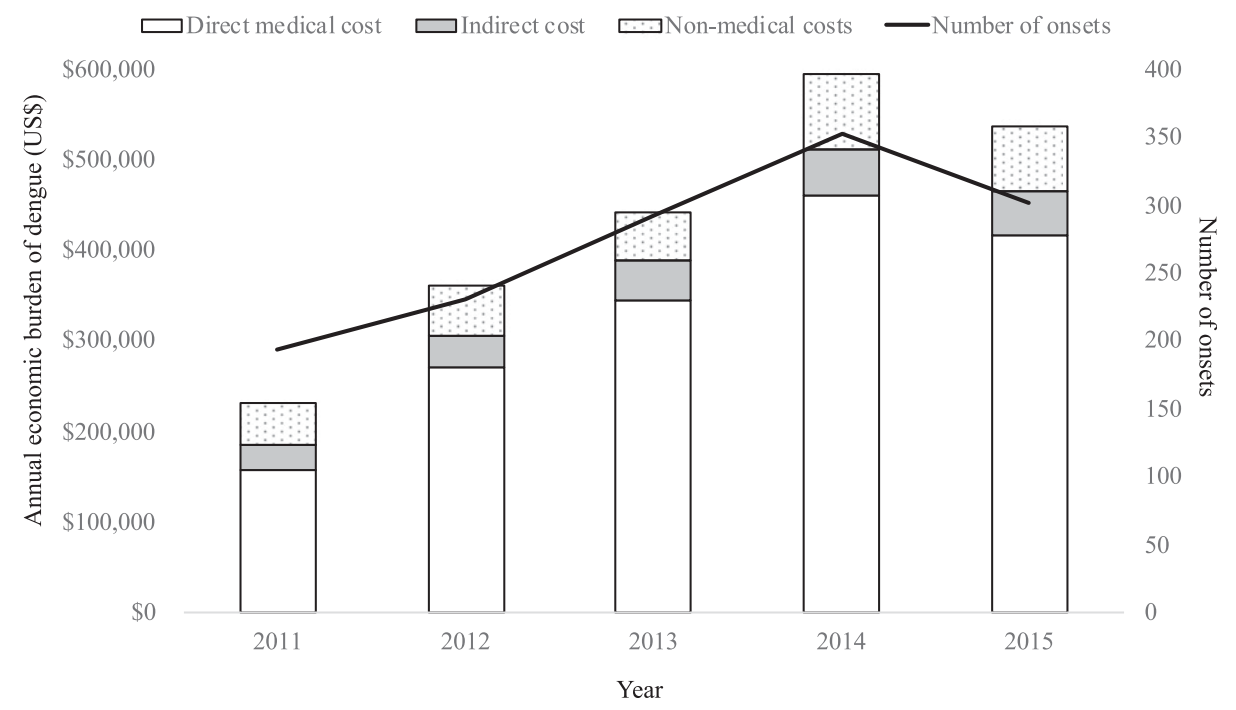

FIgURE 2. Annual economic burden of dengue in Japan from 2011 to 2015. 
TABLE 3

Parameters of sensitivity analysis for annual economic burden

\begin{tabular}{|c|c|c|}
\hline Parameter & Parameter for sensitivity analysis & References \\
\hline Number of patients, per year (scenario [a]) & $\begin{array}{l}\text { Inpatient: } 86-130 \\
\text { Outpatient: } 132-200 \\
\text { Nonmedical: } 112-170\end{array}$ & $\begin{array}{l}\text { In this research from the NDB (average } \pm \\
\text { SD), } 30\end{array}$ \\
\hline Number of patients, per year (scenario [b]) & $\begin{array}{l}\text { Inpatient: } 160-339 \\
\text { Outpatient: } 246-522 \\
\text { Nonmedical: } 210-443\end{array}$ & 30,32 \\
\hline $\begin{array}{l}\text { Average of direct medical cost (US\$/ } \\
\text { patient) }\end{array}$ & $\begin{array}{l}\text { Inpatient: } 2,775.2-3,750.7 \\
\text { Outpatient: } 198.9-283.3\end{array}$ & $\begin{array}{l}\text { The result from this research (the data not } \\
\text { excluding comorbidities) }\end{array}$ \\
\hline Average of indirect cost (US\$/patient) & $\begin{array}{l}\text { Inpatient: } 99.9-399.6 \\
\text { Outpatient: } 59.8-239.2\end{array}$ & Estimation (50-200\% of average) \\
\hline Nonmedical cost (US\$) & $\begin{array}{l}\text { Direct outside medical sector: } 2-22 \\
\text { Indirect outside medical sector: } 270-695\end{array}$ & 30 \\
\hline
\end{tabular}

The sensitivity analysis showed that annual economic burden of dengue could go up to $\$ 1,369,016$, which is considered a big impact as an imported infection. There are likely unreported domestic infection cases, such as the German patient, ${ }^{10}$ and, therefore, it is possible that many domestically infected cases were not detected or did not seek for medical care. Even in a dengue-epidemic area, there was a tendency of underreporting during non-endemic period. ${ }^{32}$ Dengue is rare in Japan, and its treatment is not specific. A dengue test may not be implemented among many cases. Moreover, dengue virus nonstructural antigen 1 is detected from the first day from the onset of illness and has high sensitivity during the first

A Number of patients from the NDB

All parameters

Number of patients

Direct medical cost of medical cases

Costs of non-medical cases

Indirect cost of medical cases

B Adjusted number of patients

All parameters

Number of patients

Direct medical cost of medical cases

Costs of non-medical cases

Indirect cost of medical cases
$\$ 319,727$

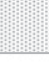

$\$ 349,860$

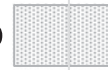

$\$ 529,330$

$\$ 439,595$

$\$ 558,959$

$\$ 412,523$

$\$ 475,268$

$\$ 418,836$

$\$ 481,027$
$\$ 765,929$

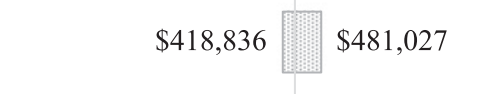

$\$ 0$

$\$ 500,000$

$\$ 1,000,000$

$\$ 1,369,016$

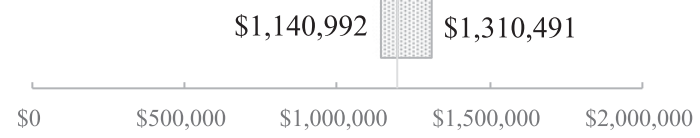

FIGURE 3. Sensitivity analysis for the annual economic burden of dengue in Japan. 
7 days. ${ }^{35}$ Its sensitivity decreases after the first 7 days, and then it is not detectable beyond day 14. Therefore, the timing of any dengue test and its sensitivity and specificity affect the reported number of dengue cases. This may result in a huge hidden economic burden by underreporting. Underreporting is a most important topic for addressing infection-mediating mosquito. Further research for this topic is expected.

Health economics evaluation, such as cost-effective analysis and budget impact analysis, has gained importance in decision-making on public health policy. Given the current levels of incidence of dengue, fatality rate, and economic burden, introducing preventive actions against dengue is not likely to be cost-effective in Japan. However, the growing number of Japanese visitors to and the inbounds from dengue-endemic countries might increase the number of the imported cases as well as a chance of restarting its domestic infections in Japan in the near future. Moreover, preventive action against dengue is likely to be effective for preventing other mosquito-borne diseases, such as chikungunya and Zika infections, in Japan. These possibilities and potential benefits need to be taken into account when dengue prevention policy is considered.

Our research had the following limitations. The NDB has no detailed clinical background data. We may not be able to exclude all the medical cost of the comorbidities that had nothing to do with dengue. Therefore, dengue-specific cost in our study might have been overestimated. Another limitation was that our research did not have any direct nonmedical cost such as transportation fee to health facilities. However, adding direct nonmedical cost would not make much difference because most people generally have good access to health facilities in Japan and the duration of the illness was shorter. Despite these limitations, the study was the first of its kind in Japan to estimate the cost of dengue using all dengue cases from the national database, and the results would be informative for further health economic research for decision-making of policy toward dengue prevention and control in Japan.

\section{CONCLUSION}

We estimated the economic burden of dengue per patient and at the national level in Japan from 2011 to 2015. The economic burden at the national level was not huge. It is considered that preventive plan for dengue is not urgent. However, dengue domestic infection may occur again in future. Preventive actions should be taken considering their cost-effectiveness or budget impact. It is expected that the results in this study can be used for health economic analysis for decision-making of not only dengue prevention strategy but also addressing mosquito-borne diseases in Japan.

Received December 7, 2019. Accepted for publication February 9, 2020.

Published online April 20, 2020.

Acknowledgments: We received the national claims data from the Japanese Ministry of Health, Labour, and Welfare. Kyorin University provided equipment for this research. We presented part of these results at the International Society for Pharmacoeconomics and Outcomes Research (ISPOR) Asia Pacific 2018, Tokyo. The members of Graduate school of International Cooperation Studies, Kyorin University and Graduate school of pharmaceutical science, Tokyo University, and the participants of ISPOR Asia Pacific 2018 gave us important advices. We appreciate them for their support and cooperation.
Financial support: This research did not receive any specific grant from funding agencies in the public, commercial, or not-for-profit sectors. Equipment and research budget of Kyorin University were used.

Disclosure: The NDB comprises anonymous data but is considered as confidential individual information. The Ethics Committee of Graduate school of International cooperation Studies in Kyorin University and the expert committee at the Ministry of Health, Labour, and Welfare in Japan approved this study before using the NDB. The Ethics Committee reviewed ethical perspective for patients, and the expert committee reviewed that we were eligible to use the national claims data appropriately.

Authors' addresses: Yusuke Kajimoto, Graduate School of Pharmaceutical Sciences, Tokyo University, Tokyo, Japan, and Global Health Research Coordinating Center, Kanagawa Institute of Industrial Science and Technology, Tokyo, Japan, E-mail: ykajimoto234@gmail.com. Tsutomu Kitajima, Faculty of Social Sciences, Kyorin University, Tokyo, Japan, E-mail: kitajima@ks.kyorin-u.ac.jp.

\section{REFERENCES}

1. World Health Organization, 2009. Dengue; Guidelines for Diagnosis, Treatment Prevention and Control, New edition. Available at: http://apps.who.int/iris/bitstream/handle/10665/44188/ 9789241547871_eng.pdf?sequence=1. Accessed November 11,2018

2. Simmons CP, Farrar JJ, Nguyen vV, Wills B, 2012. Dengue. NEngl J Med 366: 1423-1432.

3. Bhatt $S$ et al., 2013. The global distribution and burden of dengue. Nature 496: 504-507.

4. Brady OJ, Gething PW, Bhatt S, Messina JP, Brownstein JS, Hoen AG, Moyes CL, Farlow AW, Scott TW, Hay SI, 2012. Refining the global spatial limits of dengue virus transmission by evidencebased consensus. PLoS Negl Trop Dis 6: e1760.

5. Japan International Corporation of Welfare Services, 2015. Infection is Not a Problem for Single Country. - Ebola Hemorrhagic Fever, as an Example the Dengue Fever (Japnaese). Available at: https://www.mhlw.go.jp/file/06-Seisakujouhou10900000-Kenkoukyoku/0000131095.pdf. Accessed May 6, 2019.

6. Ministry of Justice, Japan, 2016. Act on the Prevention of Infectious Diseases and Medical Care for Patients with Infectious Diseases. Amendment of Act No.115 of 2014. Translation date July 13, 2016. Available at: http://www.japaneselawtranslation.go.jp/ law/detail/?re $=2 \& \mathrm{ky}=\mathrm{imm}$ unity\&ia $=03 \& \mathrm{page}=3 \& \mathrm{la}=0$. Accessed May 6, 2019.

7. Kutsuna $S$ et al., 2015. Autochthonous dengue fever, Tokyo, Japan, 2014. Emerg Infect Dis 21: 517-520.

8. Lambrechts L, Scott TW, Gubler DJ, 2010. Consequences of the expanding global distribution of Aedes albopictus for dengue virus transmission. PLoS Negl Trop Dis 25: e646.

9. Mitsuo K, 2008. Effect of the global warming on the vecter mosquitoes. $J$ Vet Epidemiol 12: 7-12.

10. Schmidt-Chanasit $J$ et al., 2014. Autochthonous dengue virus infection in Japan imported into Germany, September 2013. Euro Surveill 19: 20681.

11. Martelli CM et al., 2015. Economic impact of dengue: multicenter study across four Brazilian regions. PLoS Negl Trop Dis 9: e0004042.

12. Castro Rodriguez R, Galera-Gelvez K, López Yescas JG, RuedaGallardo JA, 2015. Costs of dengue to the health system and individuals in Colombia from 2010 to 2012. Am J Trop Med Hyg 92: 709-714.

13. Shepard DS, Halasa YA, Tyagi BK, Adhish SV, Nandan D, Karthiga KS, Chellaswamy V, Gaba M, Arora NK, The Inclen Study Group, 2014. Economic and disease burden of dengue illness in India. Am J Trop Med Hyg 91: 1235-1242.

14. Panmei K, Joseph AK, Rose W, Abraham OC, Mathuram AJ, Kumar S, Abraham AM, 2019. Direct cost of illness for dengue in hospitalized children and adults at a referral hospital in India. Int J Infect Dis 84S: S64-S67.

15. Zubieta-Zavala A, Salinas-Escudero G, Ramírez-Chávez A, GarcíaValladares L, López-Cervantes M, López Yescas JG, Durán-Arenas 
$L, 2016$. Calculation of the average cost per case of dengue fever in Mexico using a micro-costing approach. PLoS Negl Trop Dis 10: e0004897.

16. Statistics Bureau of Japan, 2012. Population Estimation (October 1, 2011) (Japanese). Available at: https://www.stat.go.jp/data/ jinsui/2011np/index.html. Accessed September 15, 2019.

17. Ministry of Health, Labour and Welfare, 2012. Basic Survey on Wage Structure Report, 2011 (Japanese). Available at: https:// www.mhlw.go.jp/toukei/itiran/roudou/chingin/kouzou/z2011/ index.html. Accessed May 6, 2019.

18. Ministry of health, Labour and Welfare, 2015. Changes in Electric Claims Data at Medical Institution Based on Numbers of Claims Data. Available at: https://www.mhlw.go.jp/file/06-Seisakujouhou12400000-Hokenkyoku/0000099002.pdf. Accessed August 8, 2018.

19. Ministry of Health, Labour and Welfare, 2018. Dengue Fever, about Notification from Physicians or Veterinarians under the Infectious Diseases Control Law (Japanese). Available at: https://www.mhlw.go.jp/bunya/kenkou/kekkaku-kansenshou11/ 01-04-19.html. Accessed May 6, 2019.

20. National Epidemiological Surveillance of Infectious Diseases NESID, 2012. National Epidemiological Surveillance of Infectious Diseases Annual Report, 2011 (Japanese). Available at: https://www.niid.go.jp/niid/ja/all-surveillance/2270-idwr/nenpou/ 3359-syulist2011.html. Accessed May 6, 2019.

21. National Epidemiological Surveillance of Infectious Diseases NESID, 2013. National Epidemiological Surveillance of Infectious Diseases Annual Report, 2012 (Japanese). Available at: https://www.niid.go.jp/niid/ja/survei/2270-idwr/nenpou/ 4307-syulist2012.html. Accessed May 6, 2019.

22. National Epidemiological Surveillance of Infectious Diseases NESID, 2014. National Epidemiological Surveillance of Infectious Diseases Annual Report, 2013 (Japanese). Available at: https://www.niid.go.jp/niid/ja/survei/2270-idwr/nenpou/ 5281-syulist2013.html. Accessed May 6, 2019.

23. National Epidemiological Surveillance of Infectious Diseases NESID, 2015. National Epidemiological Surveillance of Infectious Diseases Annual Report, 2014 (Japanese). Available at: https://www.niid.go.jp/niid/ja/survei/2270-idwr/nenpou/ 6142-syulist2014.html. Accessed May 6, 2019.

24. National Epidemiological Surveillance of Infectious Diseases NESID, 2016. National Epidemiological Surveillance of Infectious
Diseases Annual Report, 2015 (Japanese). Available at: https:// www.niid.go.jp/niid/ja/survei/2270-idwr/nenpou/6982-syulist2015. html. Accessed May 6, 2019.

25. Ministry of Health, Labour and Welfare, 2012. Annual Health, Labour and Welfare Report 2010-2011. Available at: https:// www.mhlw.go.jp/english/wp/wp-hw5/index.html. Accessed May 6, 2019

26. Ministry of Health, Labour and Welfare, 2013. Basic Survey on Wage Structure Report, 2012 (Japanese). Available at: https:// www.mhlw.go.jp/toukei/itiran/roudou/chingin/kouzou/z2012/ index.html. Accessed May 6, 2019.

27. Ministry of Health, Labour and Welfare, 2014. Basic Survey on Wage Structure Report, 2013 (Japanese). Available at: https:// www.mhlw.go.jp/toukei/itiran/roudou/chingin/kouzou/z2013/ index.html. Accessed May 6, 2019.

28. Ministry of Health, Labour and Welfare, 2015. Basic Survey on Wage Structure Report, 2014. Available at: https://www.mhlw.go.jp/ toukei/itiran/roudou/chingin/kouzou/z2014/index.html. Accessed May 6, 2019.

29. Ministry of Health, Labour and Welfare, 2016. Basic Survey on Wage Structure Report, 2015. Available at: https://www.mhlw.go.jp/ toukei/itiran/roudou/chingin/kouzou/z2015/index.html. Accessed May 6, 2019.

30. Shepard DS, Undurraga EA, Halasa YA, Stanaway JD, 2016. The global economic burden of dengue: a systematic analysis. Lancet Infect Dis 16: 935-941. (Shepard DS et al. Lancet Infectious Diseases, 2016).

31. Organisation for Economic Co-operation and Development, 2019. PPPs and Exchange Rates. Available at: https://stats.oecd.org. Accessed May 6, 2019.

32. Undurraga EA, Halasa YA, Shepard DS, 2013. Use of expansion factors to estimate the burden of dengue in Southeast Asia: a systematic analysis. PLoS Negl Trop Dis 7: e2056.

33. World Health Organization, 2018. Dengue vaccine: WHO position paper - September 2018. Wkly Epidemiol Rec 93: 457-476.

34. Kajimoto Y, Kitajima T, 2020. Clinical management of patients with dengue infection in Japan: results from national database of health insurance claims. Am J Trop Med Hyg 102: 191-194.

35. Hu D, Di B, Ding X, Wang Y, Chen Y, Pan Y, Wen K, Wang M, Che $X, 2011$. Kinetics of non-structural protein 1, IgM and IgG antibodies in dengue type 1 primary infection. Virol J 8: 47. 